\title{
Perfil de mulheres com alta fecundidade em um grande centro urbano no Brasil
}

\author{
The profile of women with high fertility \\ in a major urban center in Brazil
}

Vânia Muniz Néquer Soares ${ }^{1}$

Neia Schor ${ }^{2}$

\footnotetext{
${ }^{1}$ Pró-reitoria de Pósgraduação, Pesquisa e Extensão, Universidade Tuiuti do Paraná. R. Sidney rangel Santos, Santo Inácio. 82010-330 Curitiba PR. vaniam@onda.com.br

${ }^{2}$ Faculdade Saúde Pública,

Universidade de São Paulo.
}

\begin{abstract}
A quantitative, descriptive study sought to identify the socio-demographic, reproductive and social protection conditions of women in a large city in Brazil. The target population consisted of women living in Curitiba with the last of five or more children born in the year 2005, identified by the registration system of newborn babies. Interviews in households were carried out with 441 women from 2006 to 2008 using a semistructured questionnaire. Data obtained from the study were presented in tables with absolute and relative frequencies, averages and standard deviations. The following profile was derived from the results: migrant women from the state interior, living for over ten years in the capital, coming from large families, with a mean age of 35 years and five years of schooling, with more than one marriage, living in consensual union, underemployed, with an average income of around US\$ 352 to cover the needs of seven or more dependents. This profile clearly confirms the social vulnerability of these women and their families. The study concludes that a proactive search by family health teams for women with high fertility, in order to prioritize their needs, would assist in reducing their social and health inequalities.
\end{abstract} Key words Fertility rate, Reproductive rights, Social vulnerability
Resumo Estudo quantitativo, descritivo que teve como objetivo conhecer e caracterizar as condições sociodemográficas, reprodutivas e de proteção social de mulheres que vivenciam alta fecundidade, em um grande centro urbano. A população pesquisada constituiu-se de 441 mulheres residentes em Curitiba que tiveram o quinto filho, ou mais, no ano de 2005, identificadas pela declaração de nascido vivo do último filho. Realizaram-se visitas domiciliares para entrevistas nos anos de 2006 a 2008. Para a coleta dos dados foi utilizado um questionário semiestruturado. Os resultados foram apresentados em tabelas com frequências absolutas e relativas, médias e desvio padrão, permitindo delinear o seguinte perfil: mulher migrante do interior do estado, residente há mais de dez anos na capital, vinda de família numerosa, com 35 anos em média e cinco anos de estudo, com mais de uma união, vivendo em união consensual, subempregada, com renda média aproximada de $R \$ 600,00$, responsável por sete dependentes ou mais. Confirmando claramente a vulnerabilidade dessas mulheres e suas famílias. Conclui-se que a busca ativa de mulheres com alta fecundidade pelas equipes de saúde da família, priorizando suas necessidades, contribuiria para a redução das desigualdades sociais e em saúde a que elas estão sujeitas.

Palavras-chave Taxa de fecundidade, Direitos reprodutivos, Vulnerabilidade social 


\section{Introdução}

A Organização Panamericana de Saúde ${ }^{1}$ estima que a taxa de fecundidade total na América Latina está próxima a 2,6 filhos por mulher; contudo alerta que as iniquidades relativas às desigualdades socioeconômicas e à oferta de métodos contraceptivos são ainda preocupantes e devem ser identificadas e consideradas na elaboração de políticas sociais e de saúde em cada país.

No Brasil, os resultados da Pesquisa Nacional por Amostra de Domicílios² (PNAD) de 2007 apontam a queda da taxa de fecundidade total para níveis abaixo aos de reposição (2,1 filhos por mulheres, atingida em 2003) alcançando 1,83 filhos por mulher. Essa queda iniciou-se na segunda metade dos anos 1960 e está implicando numa desaceleração do ritmo de crescimento da população brasileira.

Embora haja tendência à homogeneização das taxas de fecundidade em níveis muito baixos em todas as regiões brasileiras, estudos referem que ainda existem diferenciais entre grupos populacionais que precisam ser identificados, com vista à superação de prováveis iniquidades sociais e em saúde reprodutiva ${ }^{3-5}$.

Segundo Berquó e Cavenaghi ${ }^{3}$, cerca de 3 milhões de mulheres brasileiras em idade reprodutiva vivenciavam uma alta fecundidade (cinco ou mais filhos) no Brasil em 2000. Estas mulheres apresentavam em média um rendimento domiciliar mensal per capita de até $1 / 4$ de salário mínimo e tinham até três anos de estudo. As autoras $^{3}$ ressaltavam por outro lado, que "pouco se sabe sobre este grupo de mulheres e do porquê de tantos filhos, questionando se seria o desejo de uma prole maior ou a falta de acesso à informação e a meios adequados para regular sua fecundidade", afirmando que "existe a necessidade urgente de estudos que possam responder a estas questões".

Estudos na área da demografia reforçam a associação entre alta fecundidade e vulnerabilidade social e em saúde reprodutiva, porém referem que a baixa fecundidade não deve ser uma meta a ser buscada ou ser imposta, uma vez que a garantia da baixa fecundidade não significa, necessariamente, que os demais aspectos fundamentais para uma saúde reprodutiva plena estejam sendo atendidos, nem garante a existência de condições propícias para uma vida e saúde melhores para as mulheres e seus filhos ${ }^{4}$.

A persistência das desigualdades sociais, de gênero e em saúde constitui um impedimento para a liberdade reprodutiva e sexual das mulhe- res brasileiras e para a melhoria das condições de vida das mulheres em geral ${ }^{6-9}$.

Deve-se considerar, portanto, que uma parcela de mulheres brasileiras encontra-se ainda fora do processo de queda da fecundidade, ou porque deseja isso, ou porque não teve oportunidade de exercer o controle sobre sua fecundidade, o que cria a necessidade de políticas e projetos que favoreçam estes subgrupos populacionais, garantindo-lhes os direitos reprodutivos, sociais e de saú$\mathrm{de}^{4}$. Conhecer estes subgrupos permitiria a escolha de estratégias de saúde e sociais mais adequadas para lhes garantir esses direitos.

As mulheres com alta fecundidade costumam ser criticadas e desvalorizadas na sociedade atual, e, por não representarem o padrão esperado de reprodução, são discriminadas mesmo por profissionais de saúde, não recebendo a devida atenção para seus problemas ${ }^{9}$. Estudos que caracterizem este grupo populacional em áreas específicas vêm sendo recomendados na área da demografia, e são importantes para a área da saúde ${ }^{3}$.

Este estudo teve por objetivo conhecer e caracterizar as condições sociodemográficas, reprodutivas e de proteção social de mulheres que vivenciam alta fecundidade na época atual, em um grande centro urbano, com vistas à identificação das desigualdades sociais e sugerir medidas de proteção social para este grupo e suas famílias.

\section{Metodologia}

Estudo de base populacional, de corte transversal e abordagem quantitativa descritiva.

A população alvo constituiu-se de todas as mulheres residentes em Curitiba que tiveram o quinto - ou mais - filho nascido vivo no ano de 2005, tendo sido identificadas pela Declaração de Nascido Vivo (DNV), obtida no banco de dados do Sistema de Informação Nacional de Nascimento (SINASC/MS), correspondendo a 723 mulheres (3\% dos 24.258 nascidos vivos de $\mathrm{Cu}-$ ritiba em 2005).

Deste total, foram entrevistadas 441 mulheres que foram localizadas em seus domicílios e aceitaram participar da pesquisa. Cerca de $60 \%$ das entrevistadas residiam e se concentravam em 9 dos 75 bairros da cidade, e em 17 bairros não havia mulheres com o quinto ou mais filho nascido vivo em 2005. Considerou-se que as mulheres que não foram encontradas apresentavam características similares àquelas presentes na população pesquisada. A coleta dos dados foi realizada entre os anos de 2006 a 2008. 
Para a coleta dos dados foi utilizado questionário semiestruturado com questões fechadas e abertas. Os resultados obtidos no estudo foram apresentados em tabelas com frequências absolutas e relativas e calculadas as médias e desvio padrão para algumas variáveis.

O estudo foi realizado em Curitiba, capital do Paraná, estado da região sul do Brasil, tida com uma das mais desenvolvidas do país, e onde as taxas de fecundidade já se encontram muito baixas ( 1,5 filhos por mulher $)^{10}$.

Este estudo constitui uma parte da pesquisa sobre "Intenções e comportamento reprodutivo de mulheres que vivenciam alta fecundidade em um grande centro urbano" - tese de doutorado aprovada em 2009 pela Faculdade de Saúde Pública da USP, e obteve financiamento da Fundação de Amparo à Pesquisa do Estado de São Paulo (FAPESP) ${ }^{10}$. A referida pesquisa foi aprovada pelo Comitê de Ética em Pesquisa da Faculdade de Saúde Pública da Universidade de São Paulo.

\section{Resultados}

Os dados sociodemográficos e referentes à procedência e tamanho de família apontaram que das 441 mulheres com alta fecundidade entrevistadas, 50,7\% nasceram no interior do Paraná e 9\% em outros estados, no entanto $79 \%$ residiam há mais de dez anos na capital. A maioria das entrevistadas provinha de famílias grandes, com uma média de cinco irmãos. A Tabela 1 evidencia outras características comentadas a seguir.

As mulheres com alta fecundidade entrevistadas se caracterizaram por um perfil etário de mais idade: o grupo de 30 a 39 anos representou $62,1 \%$ do total.

Com relação à escolaridade, 46,9\% estudaram apenas até a quarta série, $42 \%$ declararam ter cursado 8 anos de estudo ou o ensino fundamental completo e, em um patamar bem menor, $10 \%$ tinham nove ou mais anos de estudo. A média de anos de estudo deste grupo de mulheres foi de 5,1 anos de escolaridade.

A religião pode trazer subsídios sobre condicionantes de orientações, práticas e crenças que costumam impactar as decisões e/ou atitudes que as mulheres tomam em relação ao modo de vida em geral e à saúde sexual e reprodutiva em particular. A religião católica com 52\% das respostas predominou entre as entrevistadas, seguida da evangélica com 32\%, e 12\% (54 mulheres) referiram não ter nenhuma crença religiosa. As pertencentes a outras religiões apresentaram uma proporção muito baixa. Referente à raça/cor, as mulheres auto-declaradas brancas representaram $60 \%$ das entrevistadas e $39 \%$ se declararam negras (pardas, $30,7 \%$ e pretas, $8,3 \%$ ). (dados não tabulados).

A distribuição percentual das mulheres segundo o estado conjugal atual mostra que $45,4 \%$ se incluem na categoria de união consensual, $28,8 \%$ na de união legal, seguidas das mulheres separadas ou divorciadas $(13,9 \%)$, solteiras

Tabela 1. Perfil sociodemográfico das mulheres com alta fecundidade - Curitiba (2005)

\begin{tabular}{|c|c|c|}
\hline Variável & $\mathbf{N}$ & $\%$ \\
\hline \multicolumn{3}{|l|}{ Procedência } \\
\hline Curitiba & 170 & 39,5 \\
\hline Interior do Paraná & 218 & 50,7 \\
\hline Outros estados & 42 & 9,8 \\
\hline \multicolumn{3}{|c|}{ Tempo de residência em Curitiba } \\
\hline Até 2 anos & 6 & 1,9 \\
\hline 3 a 5 anos & 19 & 6,1 \\
\hline 6 a 10 anos & 39 & 12,6 \\
\hline Mais de 10 anos & 246 & 79,4 \\
\hline \multicolumn{3}{|l|}{ Número de irmãos } \\
\hline Até 2 & 61 & 14,6 \\
\hline 3 a 4 & 78 & 18,7 \\
\hline 5 ou mais & 279 & 66,7 \\
\hline \multicolumn{3}{|l|}{ Idade } \\
\hline Menos de 25 anos & 9 & 2,0 \\
\hline 25 a 29 & 62 & 14,1 \\
\hline 30 a 34 & 142 & 32,2 \\
\hline 35 a 39 & 132 & 29,9 \\
\hline 40 a 44 & 86 & 19,5 \\
\hline 45 ou mais & 10 & 2,3 \\
\hline Média \pm dp: $34,8 \pm 5,2$ & & \\
\hline \multicolumn{3}{|c|}{ Escolaridade } \\
\hline Menos de 1 ano & 23 & 5,2 \\
\hline De 1 a 4 anos & 184 & 41,7 \\
\hline De 5 a 8 anos & 189 & 42,9 \\
\hline De 9 a 11 anos & 40 & 9,1 \\
\hline 12 ou mais anos & 5 & 1,1 \\
\hline Média \pm dp: $5,1 \pm 2,9$ & & \\
\hline \multicolumn{3}{|c|}{ Religião } \\
\hline Católico Romana & 229 & 52,2 \\
\hline Evangélica & 142 & 32,5 \\
\hline Nenhuma & 54 & 12,3 \\
\hline Outras & 14 & 3,2 \\
\hline \multicolumn{3}{|l|}{ Raça } \\
\hline Branca & 260 & 60,0 \\
\hline Parda & 133 & 30,7 \\
\hline Preta & 36 & 8,3 \\
\hline Indígena & 2 & 0,5 \\
\hline Amarela & 2 & 0,5 \\
\hline
\end{tabular}

Nota: $\mathrm{N}=441$ 
$(7,8 \%)$ e viúvas $(4,1 \%)$. Observou-se ainda que 44,5\% das entrevistadas, ou 196 mulheres, tiveram mais de uma união; destas, $150(32,9 \%)$ tiveram duas ou mais uniões além da atual (Tabela 2).

Tabela 2. Caracterização do estado conjugal e dos companheiros das mulheres com alta fecundidade Curitiba (2005)

\begin{tabular}{|c|c|c|}
\hline Variável & $\mathbf{N}$ & $\%$ \\
\hline \multicolumn{3}{|l|}{ Estado conjungal } \\
\hline União consensual & 199 & 45,4 \\
\hline Casada legalmente & 126 & 28,8 \\
\hline Separada ou divorciada & 61 & 13,9 \\
\hline Solteira & 34 & 7,8 \\
\hline Viúva & 18 & 4,1 \\
\hline \multicolumn{3}{|l|}{ Tiveram mais de uma união } \\
\hline Sim & 196 & 44,5 \\
\hline Não & 244 & 55,5 \\
\hline \multicolumn{3}{|c|}{ Número de uniões além da atual } \\
\hline Uma & 88 & 20,4 \\
\hline Duas a três & 142 & 32,9 \\
\hline Mais de três & 8 & 1,8 \\
\hline \multicolumn{3}{|c|}{ Mulheres com companheiro atualmente } \\
\hline Sim & 335 & 76,0 \\
\hline Não & 106 & 24,0 \\
\hline \multicolumn{3}{|c|}{ Onde nasceu o companheiro } \\
\hline Fora de Curitiba & 188 & 59,1 \\
\hline Curitiba & 130 & 40,9 \\
\hline \multicolumn{3}{|c|}{ Tempo de residência em Curitiba } \\
\hline Até 2 anos & 6 & 3,5 \\
\hline 3 a 5 anos & 8 & 4,7 \\
\hline 6 a 10 anos & 34 & 20,0 \\
\hline Mais de 10 anos & 122 & 71,8 \\
\hline Média \pm dp: $20 \pm 11$ an & & \\
\hline \multicolumn{3}{|c|}{ Número de irmãos do companheiro } \\
\hline Até 2 & 49 & 15,5 \\
\hline 3 a 4 & 84 & 26,6 \\
\hline 5 ou mais & 183 & 57,9 \\
\hline Média \pm dp: $5 \pm 3$ & & \\
\hline \multicolumn{3}{|l|}{ Idade do companheiro } \\
\hline Menos de 25 & 16 & 4,80 \\
\hline De 25 a 29 & 42 & 12,61 \\
\hline De 30 a 34 & 60 & 18,02 \\
\hline De 35 a 39 & 81 & 24,32 \\
\hline De 40 a 44 & 70 & 21,02 \\
\hline 45 ou mais & 64 & 19,22 \\
\hline Média \pm dp: $38 \pm 8$ ano & & \\
\hline \multicolumn{3}{|c|}{ Escolaridade do companheiro } \\
\hline Menos de 1 ano & 11 & 3,4 \\
\hline De 1 a 4 anos & 108 & 32,9 \\
\hline De 5 a 8 anos & 138 & 42,1 \\
\hline De 9 a 11 anos & 63 & 19,2 \\
\hline 12 ou mais anos & 8 & 2,4 \\
\hline
\end{tabular}

Nota: $\mathrm{N}=441$
As mulheres com companheiros no momento da entrevista representavam $76 \%$ das entrevistadas (335 mulheres), e 24\% (106 mulheres) informaram não estar com companheiros, identificando-se como as únicas responsáveis pela família. Ainda relativo aos companheiros, identificou-se que menos da metade nasceu em Curitiba $(40,9 \%)$, proporção discretamente superior a de mulheres entrevistadas que nasceram na mesma cidade (39,5\%). Dos que nasceram fora de Curitiba, a maioria já reside há 10 anos ou mais na capital e, semelhante a suas companheiras, provinham de família numerosa, com cinco ou mais irmãos.

Os companheiros tinham uma média de idade de 38 anos, superior à média das mulheres ( 35 anos), e apresentavam nível de escolaridade um pouco melhor do que o de suas companheiras: $19,2 \%$ tinham 9 ou mais anos de estudo contra $10,2 \%$ das mulheres, e com uma média geral de 6,2 anos de estudo contra 5,1 das mulheres. As crenças religiosas, no entanto, eram semelhantes, predominando a religião católica, observando-se um percentual um pouco superior de homens sem nenhuma religião.

Cerca de 76,0\% dos companheiros trabalhavam no momento da entrevista, em uma proporção maior do que as mulheres (47\%). A maioria tinha ocupação na construção civil ou como autônomo, realizando serviços esporádicos como pedreiro, jardineiro, dentre outros, conforme relatavam as mulheres. Outros trabalhavam na coleta e reciclagem de papel e, em menor proporção, nas ocupações de mecânico e de motorista/ caminhoneiro, refletindo, da mesma forma que para as mulheres, o acesso predominante a ocupações que exigem pouca especialização e oferecem baixa remuneração. (dados não tabulados).

A Tabela 3 mostra a inserção das mulheres no mercado de trabalho: 208 mulheres $(47,3 \%)$ referiram estar exercendo alguma ocupação no momento da entrevista, mas $364(82,7 \%)$ afirmaram já ter trabalhado anteriormente. As ocupações atuais referidas pelas mulheres se caracterizavam pelo baixo grau de especialização e remuneração, sendo que as mais citadas foram: empregada doméstica/ diarista/ passadeira $(31,4 \%)$, catadora de papel/ recicladora $(12,4 \%)$, auxiliar de serviços gerais $(10,0 \%)$. Isto também foi observado em relação à ocupação dos companheiros, contribuindo assim para explicar a baixa renda média familiar, em torno de $\mathrm{R} \$$ 600,00 ; apenas $11 \%$ referiu renda superior a $\mathrm{R} \$$ $1.000,00$. A renda per capita mensal ficou, em média, em $\mathrm{R} \$ 90,57$, sendo ainda mais baixa para 
algumas famílias com maior número de dependentes. Chamou atenção o fato de que nove mulheres referiram renda familiar inferior a $\mathrm{R} \$$ 100,00 mensais, vivendo em extrema pobreza.

Pelo levantamento do perfil reprodutivo identificou-se que 54,6\% das mulheres tiveram a primeira relação sexual até os 15 anos, entrando precocemente no período reprodutivo, e 70,3\% tiveram uma gravidez na adolescência, sendo a média de idade no primeiro filho 18,5anos. Quanto ao número de filhos, $71 \%$ (313mulheres) tiveram entre cinco a seis filhos nascidos vivos, $24,5 \%$ tiveram de sete a nove, e mais de dez filhos $4,5 \%$, com uma média para o grupo de seis filhos nascidos vivos.

Cerca de 30\% (136 mulheres) tiveram um aborto anterior, e destas, $33 \%$ referiram mais de um aborto, não sendo questionado, no entanto, se foi espontâneo ou provocado. As complicações do aborto, como hemorragias e infecção, ocorreram para 28 mulheres. Verificou-se que

Tabela 3. Perfil econômico das mulheres com alta fecundidade - Curitiba (2005).

\begin{tabular}{|c|c|c|}
\hline Variável & $\mathbf{N}$ & $\%$ \\
\hline \multicolumn{3}{|l|}{ Trabalham } \\
\hline Sim & 208 & 47,3 \\
\hline Não & 232 & 52,7 \\
\hline \multicolumn{3}{|l|}{ Ocupações } \\
\hline $\begin{array}{l}\text { Diarista/doméstica/cuidadora/ } \\
\text { passadeira }\end{array}$ & 66 & 31,4 \\
\hline Catadora de papel/recicladora & 26 & 12,4 \\
\hline Auxiliar de serviços gerais & 21 & 10,0 \\
\hline Vendedora & 13 & 6,2 \\
\hline Cozinheira/auxiliar de cozinha & 12 & 5,7 \\
\hline Autônoma & 8 & 3,8 \\
\hline Zeladora & 8 & 3,8 \\
\hline Manicure & 6 & 2,9 \\
\hline Auxiliar administrativa/secretária & 5 & 2,4 \\
\hline Auxiliar de limpeza & 5 & 2,4 \\
\hline Outras $^{\star}$ & 40 & 19,0 \\
\hline \multicolumn{3}{|l|}{ Renda mensal (em R\$) } \\
\hline Menos de 100,00 & 9 & 2,2 \\
\hline 100,00 a 400,00 & 162 & 38,9 \\
\hline 401,00 a 600,00 & 116 & 27,9 \\
\hline 601,00 a 1000,00 & 95 & 22,8 \\
\hline 1000,00 a 2000,00 & 34 & 8,2 \\
\hline+ de 2000 & 12 & 2,9 \\
\hline \multicolumn{3}{|l|}{ Número de dependentes } \\
\hline Até 5 & 90 & 20,4 \\
\hline $6-9$ & 317 & 71,9 \\
\hline $\begin{array}{l}10 \mathrm{ou}+ \\
\text { Média } \pm \mathrm{dp}: 7 \pm 2\end{array}$ & 34 & 7,7 \\
\hline
\end{tabular}

Nota: $\left.\mathrm{n}=441{ }^{*}\right)$ Inclui 25 ocupações diferentes
86 mulheres (19,8\%) tiveram filhos nativivos que foram a óbito posteriormente, e 29 mulheres (6,6\%) tinham, além de seus filhos, algum enteado (Tabela 4).

Tabela 4. Perfil reprodutivo das mulheres com alta fecundidade - Curitiba (2005).

\begin{tabular}{|c|c|c|}
\hline Variável & $\mathbf{N}$ & $\%$ \\
\hline \multicolumn{3}{|c|}{ Idade do início da atividade sexual ${ }^{*}$} \\
\hline 10-15 anos & 236 & 54,6 \\
\hline 16-18 anos & 159 & 36,8 \\
\hline 19 ou mais & 37 & 8,6 \\
\hline \multicolumn{3}{|l|}{ Média $\pm \mathrm{dp}: 15,6 \pm 2$ anos } \\
\hline \multicolumn{3}{|l|}{ Idade no primeiro parto ${ }^{* *}$} \\
\hline$<15$ & 12 & 3,0 \\
\hline 15 a 19 & 269 & 67,3 \\
\hline 20 a 24 & 119 & 29,8 \\
\hline \multicolumn{3}{|l|}{ Média \pm dp: $18,5 \pm 3$ anos } \\
\hline \multicolumn{3}{|l|}{ Número de filhos tidos vivos } \\
\hline 5 & 213 & 48,3 \\
\hline 6 & 100 & 22,7 \\
\hline 7 & 60 & 13,6 \\
\hline 8 & 34 & 7,7 \\
\hline 9 & 14 & 3,2 \\
\hline 10 ou mais & 20 & 4,6 \\
\hline \multicolumn{3}{|l|}{ Teve algum aborto } \\
\hline Sim & 136 & 30,8 \\
\hline Não & 305 & 69,2 \\
\hline \multicolumn{3}{|l|}{ Número de abortos } \\
\hline 1 & 91 & 66,9 \\
\hline 2 & 37 & 27,2 \\
\hline 3 ou mais & 8 & 5,8 \\
\hline \multicolumn{3}{|c|}{ Quantos filhos/as vivem com a mãe } \\
\hline até 2 & 29 & 6,6 \\
\hline 3 a 6 & 359 & 81,4 \\
\hline Mais de 6 & 53 & 12,0 \\
\hline & & \\
\hline \multicolumn{3}{|c|}{$\begin{array}{l}\text { Media } \pm \text { ap: } 4,8 \pm 1,6 \\
\text { Quantos filhos/as não moram com a mãe }\end{array}$} \\
\hline até 2 & 380 & 86,2 \\
\hline 3 a 6 & 58 & 13,2 \\
\hline Mais de 6 & 3 & 0,7 \\
\hline \multicolumn{3}{|c|}{ Média $\pm \mathrm{dp}: 1,0 \pm 1,4$} \\
\hline \multicolumn{3}{|c|}{ Filhos nativivos que foram a óbito } \\
\hline $\operatorname{sim}$ & 86 & 19,8 \\
\hline não & 348 & 80,2 \\
\hline \multicolumn{3}{|c|}{ Estavam grávidas no momento da entrevista } \\
\hline $\operatorname{sim}$ & 17 & 3,9 \\
\hline não & 422 & 96,1 \\
\hline \multicolumn{3}{|c|}{ Número médio de filhos por união } \\
\hline $1^{\mathrm{a}}$. união & 4,2 & _ \\
\hline $2^{\mathrm{a}}$. união & 2,5 & - \\
\hline 3a. união & 2,0 & - \\
\hline $4^{\mathrm{a}}$. união & 1,6 & - \\
\hline 5a. união & 1,0 & - \\
\hline Fora da união & 2,0 & - \\
\hline
\end{tabular}

Nota: " $\mathrm{N}=432 ;{ }^{*} \mathrm{~N}=400$ 
Levantando-se o número de filhos por união, identificou-se uma média de quatro filhos nascidos vivos na primeira, quase três na segunda e dois na terceira.

No momento da entrevista encontravam-se novamente grávidas 17 mulheres $(3,9 \%$ do total). A maioria das mulheres $(81 \%)$ convivia na mesma moradia com três a seis filhos tidos vivos, e em média 1,0 filho não morava mais com a mãe.

Beneficiavam-se de programas sociais governamentais 281 mulheres, quase $64 \%$ das entrevistadas. No conjunto das entrevistadas, conforme demonstra a Tabela 5, 48\% recebiam bolsafamília, $28 \%$ recebiam o leite oferecido em programa do governo estadual, $16 \%$ tinham filhos na creche e $11 \%$ na pré-escola.

Referiram que precisavam da bolsa-família outras 99 mulheres (22\%), e 72 (16\%) necessita-

Tabela 5. Perfil da proteção social das mulheres com alta fecundidade e necessidades referidas para cuidar dos filhos - Curitiba (2005).

\begin{tabular}{|c|c|c|}
\hline Proteção social & $\mathbf{N}$ & $\%$ \\
\hline \multicolumn{3}{|l|}{$\begin{array}{l}\text { Recebem apoio de programas sociais } \\
\text { do governo }\end{array}$} \\
\hline Sim & 281 & 63,7 \\
\hline Não & 160 & 36,3 \\
\hline \multicolumn{3}{|l|}{$\begin{array}{l}\text { Programas de proteção social } \\
\text { referidos }\end{array}$} \\
\hline Bolsa família & 213 & 48,3 \\
\hline Programa do leite & 122 & 27,7 \\
\hline Creche & 70 & 15,9 \\
\hline Pré-escola & 49 & 11,1 \\
\hline \multicolumn{3}{|l|}{$\begin{array}{l}\text { Mulheres que necessitavam de } \\
\text { programas de proteção social }\end{array}$} \\
\hline Bolsa família & 99 & 22,4 \\
\hline Programa do leite & 72 & 16,3 \\
\hline Creche & 70 & 15, \\
\hline Pré-escola & 9 & 2, \\
\hline \multicolumn{3}{|l|}{$\begin{array}{l}\text { Necessidades apontadas pelas } \\
\text { mulheres para criar melhor dos filhos }\end{array}$} \\
\hline Ter melhor salário ou mais dinheiro & 193 & 43,76 \\
\hline Ter emprego ou emprego melhor & 116 & 26,30 \\
\hline $\begin{array}{l}\text { Ter mais vagas nas creches e pré- } \\
\text { escola }\end{array}$ & 61 & 13,83 \\
\hline Ter casa própria & 55 & 12,47 \\
\hline Ter mais ajuda do governo & 46 & 10,43 \\
\hline Ter mais tempo para os filhos & 22 & 4,9 \\
\hline Outras necessidades & 52 & $11,7 \mathrm{~s}$ \\
\hline $\begin{array}{l}\text { Não precisa de nada/ } \\
\text { responsabilidade é da família/ do } \\
\text { pai e da mãe }\end{array}$ & 80 & 18,14 \\
\hline
\end{tabular}

Obs: $\mathrm{N}=441$ vam do leite fornecido pelo Estado, outras 70 $(16 \%)$ disseram que não tiveram acesso a creche (Tabela 5).

Em questão aberta sobre o que seria necessário para cuidar melhor dos filhos, as mulheres pesquisadas priorizaram em suas respostas: melhor emprego e salário, vagas nas creches/escolas e casa própria. Para 80 mulheres (18\%) não seria necessário nenhum apoio do Estado/governo, sendo da responsabilidade da família e dos pais criar os filhos (Tabela 5).

Pelas observações e anotações de campo durante as visitas domiciliares foi possível identificar que $66 \%$ das moradias tinham condições e estruturas precárias (casas de madeira ou compensado em más condições, em favelas e invasões) e que $48 \%$ tinham condições de higiene inadequada (acúmulo de lixo dentro e fora de casa, sujeira, mau cheiro, desordem). Condições estas longe do ideal, principalmente porque nesses espaços vivia um grande número de crianças e adultos.

\section{Discussão}

Pode-se delinear por este estudo que o perfil da mulher que vivenciam alta fecundidade em $\mathrm{Cu}$ ritiba como: Mulher migrante do interior do estado, residente há mais de dez anos na capital, proveniente de família com muitos filhos, com uma média de idade de 35 anos, cinco anos de estudo em média, católica, da raça branca, com mais de uma união, vivendo atualmente em união consensual, trabalhando em subemprego, e com renda média em torno de $\mathrm{R} \$ 600,00$ para suprir as necessidades de sete dependentes ou mais.

O perfil dos companheiros dessas mulheres pode ser sintetizado da seguinte forma: Homem com uma média de 38 anos de idade, seis anos de estudo, religião católica, nascido fora de Curitiba, com cinco ou mais irmãos e trabalhando em ocupações geralmente precárias.

Perfil que confirma claramente a vulnerabilidade social destas mulheres e suas famílias, apontado em outros estudos ${ }^{3,4}$. Perfil esse que pode ter contribuído para dificultar a regulação da fecundidade das mulheres pesquisadas e influenciado para a manutenção da alta fecundidade.

Estudos apontam que melhor nível de instrução e renda permite às pessoas maior percepção dos problemas de saúde e entendimento das informações sobre saúde; a adoção de estilo de vida saudável; o consumo e a utilização dos serviços de saúde; e a adesão aos procedimentos terapêuticos ${ }^{11}$. 
Assim, a garantia de maior escolaridade, trabalho formal e renda, além do acesso a informações sobre direitos e saúde reprodutiva relacionadas às questões de gênero, e a métodos contraceptivos adequados para os casais, contribuiria para a redução das altas taxas de fecundidade relacionadas às gestações indesejadas ou não planejadas. O desconhecimento sobre as questões relacionadas aos direitos e à saúde reprodutiva $\mathrm{e}$ sexual contribui para a manutenção das desigualdades de gênero no controle sobre a reprodução, especialmente nas camadas populares, nas quais se inseria a maior parte das entrevistadas desta pesquisa.

As mulheres deste estudo iniciaram precocemente a vida sexual, e em uma época em que o acesso às orientações e aos métodos contraceptivos ainda eram mais restritos, com a primeira relação ocorrendo em média aos 15 anos. A pesquisa nacional de demografia e saúde da criança e da mulher, PNDS 2006, identificou que a média de idade da primeira relação sexual das mulheres brasileiras foi em média aos $17 \operatorname{anos}^{12}$. A associação entre as variáveis - idade, primeira relação sexual, primeira união e primeiro filho e fecundidade futura - está estabelecida na literatura nacional e internacional. De forma geral, quanto mais cedo se dão a primeira relação sexual e a primeira união, maior a chance de o primeiro nascimento também acontecer mais cedo e maior a chance de progressão para parturições de ordens superiores e de se atingir uma alta parturição ${ }^{1-4}$.

Estudos têm evidenciado situações de vulnerabilidade no uso dos métodos contraceptivos, por desconhecimento e despreparo, especialmente de jovens de classes populares, na primeira relação sexual, determinando em muitos casos a gravidez ainda na adolescência. Contribuem para esta situação as desigualdades de gênero (cabendo às meninas a preocupação exclusiva com a contracepção) e os obstáculos sociais para a regulação da sexualidade, como as precárias iniciativas de formação em sexualidade, saúde reprodutiva e gênero nas escolas, unidades de saúde e na família, que levem em conta o aprendizado da autonomia e responsabilidade no exercício sexual, além restrição a alguns métodos contraceptivos, impostas muitas vezes por profissionais de saúde pouco preparados para atender aos adolescentes ${ }^{13,14}$.

A média de idade das mulheres com alta fecundidade ao ter o quinto filho era de 35 anos, devendo-se ressaltar, no entanto, que $16,1 \%$ tinham menos de 29 anos, e poderiam continuar reproduzindo por um longo período, aumentando sua prole para além do quinto filho, se não houver uma busca ativa destas mulheres para identificar suas necessidades de contracepção e incluí-las nos programa de planejamento familiar.

Quanto à conjugalidade das mulheres pesquisadas observou-se um perfil diferente em relação ao das mulheres do país, levantado pela PNDS 2006, em que 64\% das mulheres se encontravam em união (36,7\% formalmente e $27,3 \%$ informalmente $)^{12}$. No grupo em estudo, $74 \%$ se declararam unidas, sendo $29 \%$, formalmente, e $45 \%$ informalmente, e $24 \%$ das mulheres encontravam-se sem companheiros, tendo que assumir sozinhas os custos da casa e a criação dos filhos, aumentando a fragilidade social destas famílias.

No perfil reprodutivo chamou a atenção que $30 \%$ tiveram sete filhos ou mais e quase $4 \%$ das mulheres entrevistadas estavam grávidas novamente, embora a última gravidez tivesse ocorrido há menos de dois anos. Esses achados reforçam a idéia de possíveis falhas dos serviços de saúde, tanto na atenção integral à saúde das mulheres como na saúde reprodutiva e planejamento familiar, ainda na atualidade, mesmo nas capitais e em muitos municípios que não assumiram esta atividade essencial da atenção básica ${ }^{15}$.

A maioria dos filhos morava ainda com a mãe, sobrevivendo, no entanto, com baixíssima renda e precárias condições de vida. O perfil reprodutivo demonstrou ainda, além de elevada média de filhos, alta proporção de abortos e de filhos nascidos vivos que foram a óbito, em torno de $30 \%$ e $20 \%$ das mulheres, respectivamente.

Scavone ${ }^{9}$ refere que a maternidade, especialmente nos países em desenvolvimento, como o Brasil, constitui um fenômeno social marcado pelas desigualdades sociais, raciais/étnicas e pelas questões de gênero. Consequentemente, as mudanças e as implicações sociais da realização dessa experiência não atingem, da mesma forma, todas as mulheres.

Os padrões sexuais e reprodutivos variam de acordo com as regiões, e essas diferenças se devem a inúmeros fatores como: condições socioeconômicas, diferenças culturais, e acesso a serviços de saúde ${ }^{16}$.

As transformações sociais, econômicas, culturais e políticas são determinantes das mudanças observadas nos padrões reprodutivos das mulheres nas últimas décadas no Brasil como em outros países industrializados. Entretanto, essas transformações não atingiram igualmente todas as mulheres, e os diferenciais de fecundidade refletem, desta forma, as iniquidades sociais e em saúde a que estão expostas muitas mulheres ${ }^{3,4}$. 
Uma parcela das mulheres entrevistadas referiu não ter tido acesso aos recursos de proteção social e indicaram que a falta de creche e de escolas com horários mais abrangentes era um grande empecilho a seu acesso a um trabalho formal, dentre outras dificuldades.

Conforme ressalta Itaborai ${ }^{17}$, as famílias exercem importante papel na reprodução biológica, na reprodução social e na construção de identidade dos indivíduos, e deveriam ser mais valorizadas e reconhecidas nas suas diferentes formas de constituição, pelas políticas públicas.

O Estado tem presença na regulação da vida familiar, tanto pelo que ele afirma - na legislação, nas políticas públicas - quanto pela sua omissão ${ }^{17,18}$.

Para Goldani ${ }^{19}$, historicamente no Brasil existe uma tendência à sobrecarga da família diante da incapacidade do mercado e do Estado de prover segurança material às pessoas. Ao analisar a família como fator de proteção social, concluiu que ocorre a absorção por parte das famílias de maiores responsabilidades diante da fragilidade das ações estatais, amortizando o impacto das políticas econômicas e da reestruturação capitalista sobre o mercado de trabalho.

No Brasil os programas de proteção social são criticados por propiciarem apenas o alívio à pobreza e não combaterem a pobreza, uma vez que não atacam os determinantes estruturais das desigualdades sociais, com vistas a uma real melhora das condições de vida e cidadania da população ${ }^{17,18}$.

A organização de serviços de saúde e educação de qualidade, para a garantia de uma adequada socialização das crianças e jovens, é essencial ao desenvolvimento e uma questão de justiça social $^{17,18}$.

Considerando que crianças e adolescentes possuem peculiaridades biopsicossociais relacionadas ao processo de crescimento, desenvolvimento pessoal e inserção social, caracterizandose como grupo de alta vulnerabilidade aos agravos sociais, a perspectiva de trabalho voltado para a proteção e a promoção da qualidade de vida para a infância e adolescência deve compreender uma dimensão integradora entre múltiplos setores para a mobilização das intervenções interinstitucionais e interpessoais reconhecida como trabalho em rede. Existe consenso quanto à eficácia e operacionalidade das redes de proteção com o objetivo comum de melhorar o impacto e as ações, em atendimento às demandas, permitindo a descentralização quanto à tomada de decisões e à concretização das ações. Diante dos diferentes níveis de complexidade e especifi- cidades de cada setor (jurídico, educacional, saúde, assistência social, outros), essa rede possibilitaria a agregação de propostas e responde melhor às necessidades, na garantia dos direitos e atenção global a criança e adolescentes, assim como na resolutividade dos problemas individuais e coletivos ${ }^{20}$.

A Comissão Nacional sobre Determinantes Sociais da Saúde ${ }^{11}$ por sua vez refere que o Programa Bolsa-Família deveria ser operado intersetorialmente, no entanto não foi ainda observada a recomendação de uma articulação efetiva e pró-ativa de ações de saúde e educação dirigidas aos beneficiários da transferência de renda. Em muitos municípios, as secretarias setoriais não se articulam para a oferta comum de serviços aos que recebem a bolsa família, e a intersetorialidade do programa se dá apenas no nível da informação, quanto ao registro de frequência escolar e acompanhamento em saúde.

O sistema de saúde, como uma política setorial isolada, não consegue acompanhar a complexidade urbana atual. Estudos mostram que alguns desafios à expansão e consolidação da Atenção Básica e do Programa Saúde da Família (PSF) nos municípios com mais de 100 mil habitantes não decorrem somente dos desafios enfrentados pelo próprio setor saúde, mas também à complexa dinâmica da urbanização brasileira, onde metrópoles abrigam um paradoxo: as melhores infraestruturas e os mais altos índices de riqueza com a desigualdade e a impossibilidade de acesso de muitos cidadãos aos serviços públicos. A política de Atenção Básica deve nesse sentido associar-se a uma política de desenvolvimento urbano, que inclua a garantia de habitação, transporte e saneamento básico, que têm reflexos importantes nas condições de vida e saúde da população. O financiamento e o planejamento estratégico do sistema de saúde têm que considerar as adversidades e as velhas e novas demandas geradas nas grandes cidades ${ }^{21}$.

Observou-se que mulheres que vivenciam alta fecundidade na atualidade, mesmo em um grande centro urbano como Curitiba, tida como uma das cidades mais desenvolvidas do sul do Brasil, experimentam processos de exclusão social, como privações e abandono, estando em sua maioria impossibilitadas de partilhar benefícios produzidos pela sociedade, e atingir a plena cidadania ${ }^{16}$.

A OPAS, ao analisar o progresso alcançado em relação ao compromisso mundial, expresso nos Objetivos do Desenvolvimento do Milênio (ODM), estabelecidos pelas Nações Unidas, dentre eles o terceiro objetivo - promover a igualda- 
de entre os sexos e a autonomia da mulher - refere que uma das principais restrições para completar a agenda da assistência básica de saúde é a situação das mulheres, uma vez que estas já representam mais de dois quintos da força de trabalho na América Latina e no Caribe, no entanto têm seu progresso econômico reduzido devido a dificuldades para obter trabalhos remunerados, ganham menos, não tendo acesso a algumas ocupações, sendo a sua participação no setor informal desproporcionadamente maior. Ressalta o documento que sucesso em - promover a igualdade entre os sexos e a autonomia da mulher produziria o "dividendo duplo" de melhorar as vidas tanto das mulheres como das crianças ${ }^{1}$.

\section{Conclusões}

Conclui-se que mulheres com alta fecundidade continuam vivendo com seus filhos em precárias condições sociais e de vida, em situação de exclusão social, mesmo em grandes centros urbanos do país, refletindo desigualdades crônicas, tanto sociais como de saúde e de gênero, da realidade brasileira.

A busca ativa e a vigilância em saúde de grupos vulneráveis, incluindo as mulheres com alta fecundidade e suas famílias, pelas equipes de saúde da família, poderia atenuar as desigualdades sociais e em saúde desses grupos, com vistas ao planejamento de medidas intersetoriais que promovam melhores condições de vida e saúde. A declaração de nascidos vivos, e o SINASC fornecem informações que permitem a localização desse e de outros grupos vulneráveis.

É indispensável a promoção e a implementação de políticas compatíveis para a realização da maternidade, a garantia dos direitos sexuais e reprodutivos, mas por outro lado é indispensável que se adotem medidas efetivas de proteção social para as mulheres e seus filhos.

\section{Colaboradores}

VMN Soares e N Schor participaram igualmente de todas as etapas de elaboração do artigo. 
Referências

1. Organización Panamericana de la Salud. Salud en las Américas 2007. [acessado 2008 out 8]. Disponível em: http://www.paho.org/hia/vol1 regional.html.

2. Instituto de Pesquisa Econômica Aplicada. Pnad 2007: Primeiras análises - Demografia e Gênero. Brasília: IPEA; 2008. [acessado 2008 nov 30]. Disponível em: http://www.ipea.gov.br/pnad/

3. Berquó E, Cavenaghi S. Mapeamento sócio-econômico e demográfico dos regimes de fecundidade no Brasil e sua variação entre 1991 e 2000 . In: 14 Encontro Nacional de Estudos Populacionais; 2004 [acessado 2005 jun 8]. Disponível em: www.abep. org.br.

4. Caetano AJ. O declínio da fecundidade e suas implicações. In: Anais do Seminário Tendências da Fe cundidade e Direitos Reprodutivos no Brasil; 2004 [acessado 2005 jul 8]. Disponível em: http:// www.abep.nepo.unicamp.br/.

5. Morell MGG, Campanário PR. Hipótese da homogeneização da anticoncepção: evidências para uma polêmica. In: Anais do X Encontro Nacional de Estudos Populacionais; 1996; Caxambu: ABEP; 1996.

6. Arilha M. Contracepção, empowerment e entitlement: um cruzamento necessário na vida das mulheres. In: Bérquó E. Reflexões sobre gênero e fecundidade no Brasil. Durham: Family Health International; 1995.

7. Ávila BA. Direitos Sexuais e Reprodutivos: desafios para as políticas de saúde. Cad Saude Publica 2003; 19(Supl. 2):465-469.

8. Jelin E. Familia y género: notas para el debate. Rev Estudos Feministas 1995; 2:394-413.

9. Scavone L. Dar vida e cuidar da vida: Feminismo e Ciência. São Paulo: UNESP; 2004.

10. Soares VMN. Intenções e comportamento reprodutivos de mulheres que vivenciam alta fecundidade em um grande centro urbano [tese]. São Paulo: Faculdade de Saúde Pública; 2009.

11. Comissão Nacional sobre Determinantes Sociais da Saúde. As causas sociais das iniquidades em saúde no Brasil: Relatório final da Comissão Nacional sobre Determinantes Sociais da Saúde. Rio de Janeiro: CNDSS; 2008 [acessado 2008 set 26]. Disponível em http://www.cndss.fiocruz.br/pdf/home/relatorio. pdf.

12. Brasil. Ministério da Saúde (MS). Pesquisa Nacional de Demografia e Saúde da Criança e da Mulher em 2006. Brasília: MS; 2008.
13. Alves CA, Brandão ER. Vulnerabilidade no uso de métodos contraceptivos entre adolescentes e jovens: interseções entre politicas e atenção à saúde. Cien Saude Colet 2009; 14(2):661-670.

14. Veiga MBA, Pereira AL. Opinião de jovens do sexo masculino sobre contracepção, gravidez não planejada e aborto induzido. Cienc Cuid Saude 2010; 9(4):682-689.

15. Osis MJD, Fagundes A, Makuch MY, Mello MB, Sousa MH, Araújo MJO. Atenção ao planejamento familiar no Brasil hoje: reflexões sobre os resultados de uma pesquisa. Cad Saude Publica 2006; 22(11):2481-2490.

16. Duarte CM, Nascimento VB, Akerman M. Gravidez na adolescência e exclusão social: análise de disparidades intra-urbanas. Rev Panam Salud Publica 2006; 19(4):236-243.

17. Itaboraí NR. A proteção social da família contemporânea: reflexões sobre a dimensão simbólica das políticas públicas. In: Anais do Seminário as Famílias e as Políticas Públicas; 2005. [acessado 2009 jan 20]. Disponível em: http://www.abep.nepo.unicamp.br/docs/ anais/outros/FamPolPublicas/NathalieItaborai.pdf

18. Associação Brasileira de Estudos Populacionais. Mesa redonda sobre Proteção Social e Família. In: Anais do Seminário as Famílias e as Políticas Públicas; 2005. [acessado em $2008 \mathrm{dez}$ 10]. Disponível em: http://www.abep.org.br.

19. Goldani AM. O regime demográfico brasileiro nos anos 90: desigualdades, restrições e oportunidades demográficas. In: Galvão L, Díaz JG, organizadores. Saúde sexual e reprodutiva no Brasil. São Paulo: Hucitec, Population Council; 1999. p. 25-69.

20. Costa MAO, Bigras M. Mecanismos pessoais e coletivos de proteção e promoção da qualidade de vida para a infância e adolescência. Cien Saude Colet 2007; 12(5):1101-1109.

21. Viana ALA, Machado CV. Proteção social em saúde: um balanço dos 20 anos do SUS. Physis Revista de Saúde Coletiva 2008; 18(4):645-684.

Artigo apresentado em 12/08/2011

Aprovado em 10/09/2011

Versão final apresentada em 12/10/2011 